\title{
Utility of a dual immunostain cocktail comprising of p53 and CK20 to aid in the diagnosis of non-neoplastic and neoplastic bladder biopsies
}

\author{
Isil Z Yildiz*1, Rosemary Recavarren ${ }^{1}$, Henry B Armah ${ }^{1}$, Sheldon Bastacky ${ }^{2}$, \\ Rajiv Dhir ${ }^{1}$ and Anil V Parwani ${ }^{1}$
}

\begin{abstract}
Address: ${ }^{1}$ Department of Pathology, Shadyside Hospital, University of Pittsburgh Medical Center, Pittsburgh, Pennsylvania, USA and ${ }^{2}$ Department of Pathology, Presbyterian University Hospital, University of Pittsburgh Medical Center, Pittsburgh, Pennsylvania, USA

Email: Isil Z Yildiz* - isilzennure@gmail.com; Rosemary Recavarren - recavarrenra@upmc.edu; Henry B Armah - armahh2@upmc.edu; Sheldon Bastacky - bastackysi@msx.upmc.edu; Rajiv Dhir - dhirr@msx.upmc.edu; Anil V Parwani - parwaniav@upmc.edu

* Corresponding author
\end{abstract}

Published: 14 October 2009

Diagnostic Pathology 2009, 4:35 doi:10.1186/1746-1596-4-35

This article is available from: http://www.diagnosticpathology.org/content/4/I/35

(C) 2009 Yildiz et al; licensee BioMed Central Ltd.

This is an Open Access article distributed under the terms of the Creative Commons Attribution License (http://creativecommons.org/licenses/by/2.0), which permits unrestricted use, distribution, and reproduction in any medium, provided the original work is properly cited.

\begin{abstract}
Background: Distinction between non-neoplastic and neoplastic bladder lesions is therapeutically and prognostically important. Our objective is to describe the use of double immunohistochemistry (DIHC) for $\mathrm{p} 53+\mathrm{CK} 20$ as a tool for diagnosing neoplasia in bladder biopsies.

Methods: $\mathrm{p} 53+\mathrm{CK} 20$ DIHC were examined in 38 reactive atypia, 10 dysplasia, 9 carcinoma in situ (CIS) and 7 invasive carcinoma (IC) cases. CK20 was evaluated according to distribution extent and degree of intensity whereas percentage of positive cells together with staining intensity was taken into account in the evaluation of $\mathrm{p} 53$.

Results: $92 \%$ of reactive cases were either CK20(-) or (+) only in the upper $1 / 3$ urothelium. In dysplastic cases CK20 staining distribution was as follows: $60 \%$ in $2 / 3$ of the urothelium, $30 \%$ full thickness, $10 \%$ in the upper $1 / 3$ urothelium. Among CIS cases, $89 \%$ had full thickness CK20 positivity, of which $62 \%$ were $\mathrm{p} 53(+) .71 \%$ of IC cases exhibited strong and full thickness dual staining.

Conclusion: This is the first study in the literature to use DIHC of p53+CK20 in distinction of non-neoplastic and neoplastic bladder lesions. Dual staining by $\mathrm{p} 53+\mathrm{CK} 20$ cocktail allows for histologic correlation and diminishes the risk of losing the area of interest in limited biopsy specimens.
\end{abstract}

\section{Background}

Urothelial carcinoma is the $7^{\text {th }}$ most common cancer worldwide with 260,000 new cases in men and 76,000 cases in women per year [1]. Furthermore, it is the $4^{\text {th }}$ leading cause of cancer in American men with 14,100 deaths per year in the US [2].
2004 World Health Organization/International Society of Urological Pathology (WHO/ISUP) consensus committee classifies flat urothelial lesions with atypia as reactive urothelial atypia (RUA), atypia of unknown significance (AUS), urothelial dysplasia (UD) and carcinoma in situ (CIS) $[1,3]$. UD is defined by "appreciable loss of polarity 
with nuclear rounding and crowding and cytologic atypia that is not severe enough to merit a diagnosis of CIS." whereas AUS is a descriptive category for cases in which dysplasia cannot be ruled out for sure, because of a degree of atypia that is discordant with the extent of inflammation [1]. Both UD and CIS are precursor lesions of invasive carcinoma and their presence is associated with a high risk of progression and recurrence [3-5]. Although the morphologic criteria is very useful, CIS diagnosis may be challenging in cases where the reactive/therapy atypia is in the differential diagnosis. Generally, in reactive atypia, polarity is maintained and accompanying inflammation or history of reactive conditions (calculi, trauma, instrumentation or infection) may be present and cells lack irregular chromatin distribution and pleomorphism. The presence of large, irregular, hyperchromatic nuclei, large nucleoli, and frequent mitoses including atypical ones in the midurothelium to upper urothelium raise the possibility of CIS [1]. However, some patterns of CIS lack pleomorphism and may mimic reactive atypia [6]. CIS cases with scattered atypical cells and pagetoid spread may be underdiagnosed because of the absence of full-thickness atypia and may be overlooked as non-neoplastic lesions [7].

Persistent UD or CIS in a background of therapy is considered as therapy failure and may lead to radical cystectomy. Therefore differentiating UD and CIS from RUA in the background of inflammatory/post-therapy changes is critical because of appearent therapeutic and prognostic implications. Other reasons such as small specimen size and interobserver differences may also contribute to difficulties in making the correct diagnosis [7]. Morphology alone may not be sufficient in the differentiation. Hence, in diagnostically difficult cases of AUS, specific markers of UD and CIS to enhance morphology would be of great utility to pathologists in distinguishing RUA from UD and CIS.

In the search for reliable markers; p53 and cytokeratin 20 (CK20) are emerging as useful indicators of neoplastic change and prognosis in urothelial proliferations as the reports in favor of them accumulate [8-12].

\section{Methods}

64 bladder biopsies, consisting of 38 benign/reactive, 10 dysplasia, 9 CIS, and 7 invasive carcinoma (IC) (6 papillary, 1 flat) cases, were retrieved from our surgical pathology files. The samples were fixed in $10 \%$ buffered formalin solution and embedded in paraffin blocks. The biopsies were diagnosed according to the 2004 WHO classification of tumors of the urinary system [1].

Sections $(4 \mu \mathrm{m})$ from each case were obtained. Deparaffinization, rehydration, and antigen unmasking were achieved by boiling sections in a commercially available steamer. After quenching endogenous peroxidase, slides were incubated with a cocktail of p53+CK20 composed of $10 \mathrm{ul}$ of anti-p53 polyclonal antibody (1:500; DAKO, Carpinteria, CA), 50 ul of anti-CK20 monoclonal antibody (1:100; DAKO, Carpinteria, CA) and 4,940 ul of Van Gogh Yellow diluent. The detection system used was a double stain polymer detection kit.

H\&E and double immunohistochemistry (DIHC) of p53+CK20 were examined for each case. Nuclear staining for p53 and cytoplasmic staining for CK20 were interpreted as positive. p53 was evaluated according to the ratio derived from the number of p53-positive cells and staining intensity and scored as: 0 (no staining), 1+ ( $<15 \%$ cells, weak), $2+(15-50 \%$ cells, moderate $), 3+$ ( $>50 \%$ cells, strong) by semi-quantitative reassortment. CK20 cytoplasmic stain was also semiquantitatively evaluated: 0 (no staining), $1+$ (patchy, weak), $2+(<50 \%$ cells, moderate), $3+(>50 \%$ cells, strong $)$. CK20 $(+)$ cells were additionally described by location: Upper $1 / 3$ urothelium including umbrella cells, 2/3 urothelium sparing basal layer and full-thickness staining including the basal layer.

\section{Results}

35 out of 38 (92\%) benign/reactive cases were either CK20(-) or showed CK20 positivity only in the upper $1 / 3$ urothelium including umbrella cells and the majority, 21 out of $35(60 \%)$, of these cases were p53(-). The remaining 3 out $38(8 \%)$ cases showed variable CK20 staining wheras 14 out of $35(40 \%)$ showed weak $(1+)$ p53 positivity (Figure 1).

Among dysplastic cases, 6 out of 10 cases (60\%) exhibited CK20 positivity in 2/3 of the urothelium sparing the basal layer while 3 cases (30\%) showed full-thickness CK20 positivity, only 1 of which was accompanied by $3+$ p53 positivity and 1 out 10 dysplastic $(10 \%)$ cases was CK20(+) only in $1 / 3$ superficial urothelium (Figure 2 ).

8 of $9(89 \%)$ CIS cases showed focal or diffuse full-thickness CK20 positivity and 5 out of those $8(62 \%)$ were $3+$ p53(+). 1 of the CIS cases (11\%) showed CK20 positivity only in the upper $1 / 3$ urothelium accompanied by strong $3+$ p53 positivity involving the basal layer (Figure 3).

Among invasive carcinoma cases, 5 of 7 (71\%) were fullthickness CK20 positive, 2 of those cases $(40 \%)$ showed $3+$ p 53 positivity whereas other 2 cases $(40 \%)$ showed $2+$ p53 positivity. The remaining 2 out of $7(29 \%)$ cases showed CK20 positivity other than full thickness whereas 3 out of 7 (43\%) cases were p53(-) or showed weak p53 positivity. In dually positive cases, CK20 and p53 occupied the full-thickness urothelium, including the basal layer (Figure 4). 

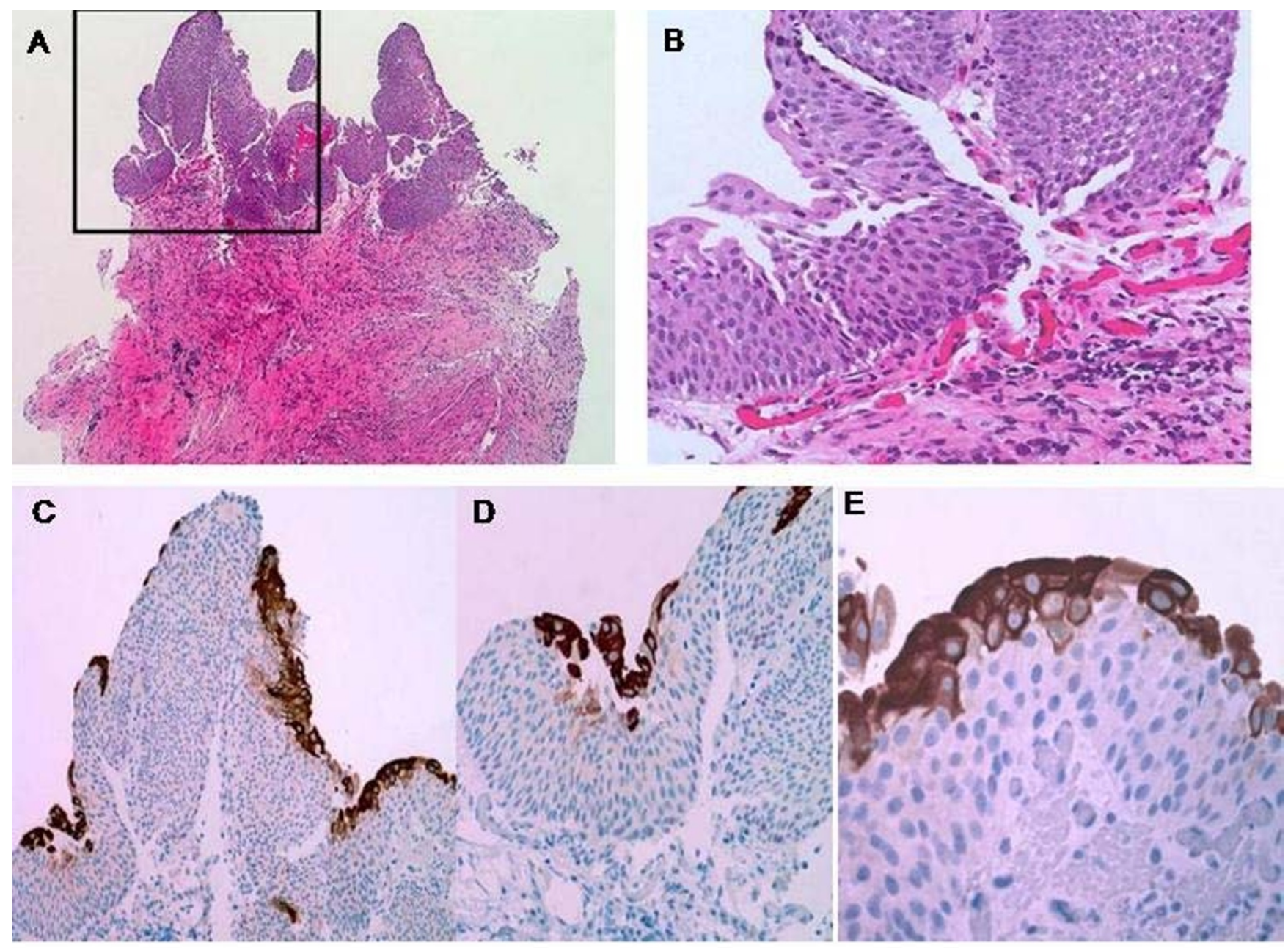

\section{Figure I}

Reactive urothelium (A and B) (hematoxylin eosin, original magnifications $\times 40$ (A), $\times 200$ (B)). Cytoplasmic immunoreactivity in reactive urothelium to CK20 in I/3 urothelium including umbrella cells (original magnifications $\times 40$ (C), $\times$ $200(\mathrm{D}), \times 400(\mathrm{E}))$.

The distribution of location of CK20 and presence of p53 staining according to diagnosis groups are given on Figure 5.

\section{Discussion}

The problem of distinction between reactive and dysplastic atypical changes in the urothelium has not been resolved, even after $2004 \mathrm{WHO} / \mathrm{ISUP}$ classifications [1,3]. Much inter and intraobserver disagreement constitute a dilemma due to lack of definite morphological criteria to diagnose CIS, dysplasia and reactive atypia.

CIS is a high-grade intraurothelial neoplasm. Patients with CIS are at significant risk for the development of invasive urothelial carcinoma, cancer recurrence, progression, and even death from bladder cancer $[3-5,13,14]$. Therefore the recognition of CIS in bladder biopsy speci- mens is of great importance because it not only has important prognostic implications but may also alter subsequent therapy. The histopathology of urothelial CIS may overlap with RUA resulting in diagnostic difficulty when interpreting bladder biopsies [9]. The difficulty and importance of distinguishing CIS from benign atypias should not be underrated as malpractice cases involving the failure to recognize CIS are growing in number [15]. Dysplastic intraepithelial lesions are another problematic area that requires distinction from CIS and which pathologists frequently feel uncomfortable evaluating on the basis of histological criteria alone.

As the distinction is therapeutically and prognostically critical, objective ancillary markers to help in the histologic differentiation between CIS and dysplasia and reactive atypia are necessary. Importance of special and 


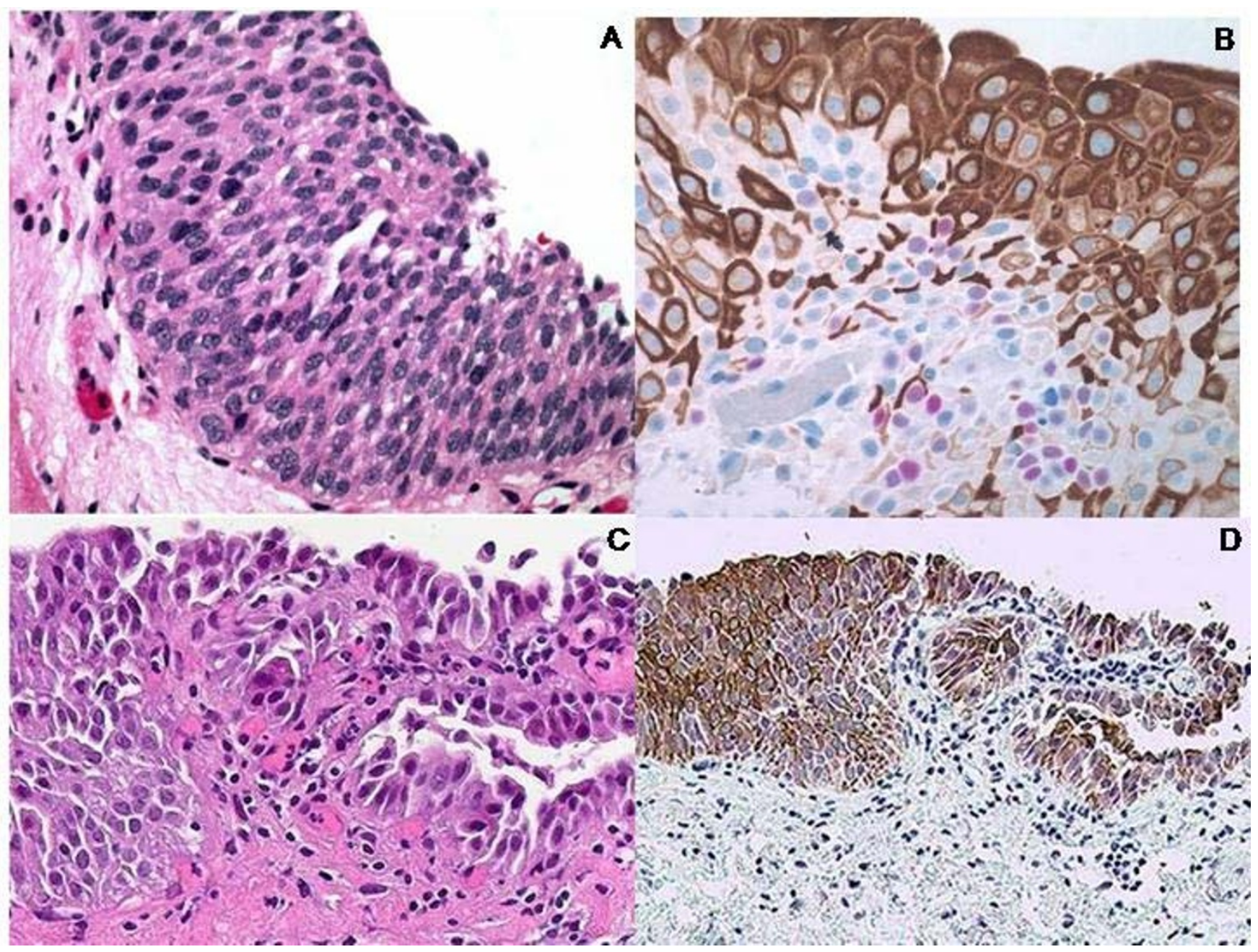

Figure 2

Dysplastic urothelium (A and C) (hematoxylin eosin, original magnifications $\times$ 200). Cytoplasmic immunoreactivity in dysplastic urothelium to CK20 in 2/3 of the urothelium sparing the basal layer and nuclear 2+ immunoreactivity to p53 (original magnification $\times 200$ (B)). Cytoplasmic full-thickness immunoreactivity in dysplastic urothelium to CK20 (original magnification $\times 100(D))$.

immunohistochemical stains for correct diagnosis and accurate subclassification of controversial cases in other lesions of urinary tract are also emphasized recently by Jin et al [16] and Pradhan et al [17]. Previous studies have demonstrated the diagnostic utility of separate p53 and CK20 immunohistochemistry (IHC) in assessing neoplasia in bladder biopsies [11]. These markers are known to be easy to manage and interpret. Distinctive immunoreactivity patterns with antibodies against p53 and CK20 were identified for reactive atypia and CIS [9]. Abnormal CK20 expression in urothelial cells accompanied by overexpression of p53 are considered indicators of dysplastic change in urothelial mucosa and immunostaining with p53 and CK20 may help accurately diagnose CIS $[11,18]$.

To our knowledge, no previous study in the literature has used DIHC of p53+CK20 in distinction of non-neoplastic and neoplastic bladder lesions. In this study, we investigated the utility and advantages of p53+CK20 DIHC as a tool for detecting synchronous expression of both markers in bladder biopsies and for objectively distinguishing the cases with CIS and dysplastic urothelial changes from reactive nonneoplastic atypia.

The nuclear overexpression of p53 by immunohistochemistry has been shown to be representative of p53 tumor suppressor gene mutation which is a common event in neoplastic urothelium [19-26]. p53 is considered to be nonexpressed in the nonneoplastic urothelium and overexpression of the p53 gene product has been reported as a marker of progression in urothelial carcinoma $[24,25,27$ 29]. Mutations of the p53 gene and immunohistochemical positivity for the p53 protein have been found in $40 \%$ to $60 \%$ of urothelial carcinomas in studies of Olumi, Sid- 

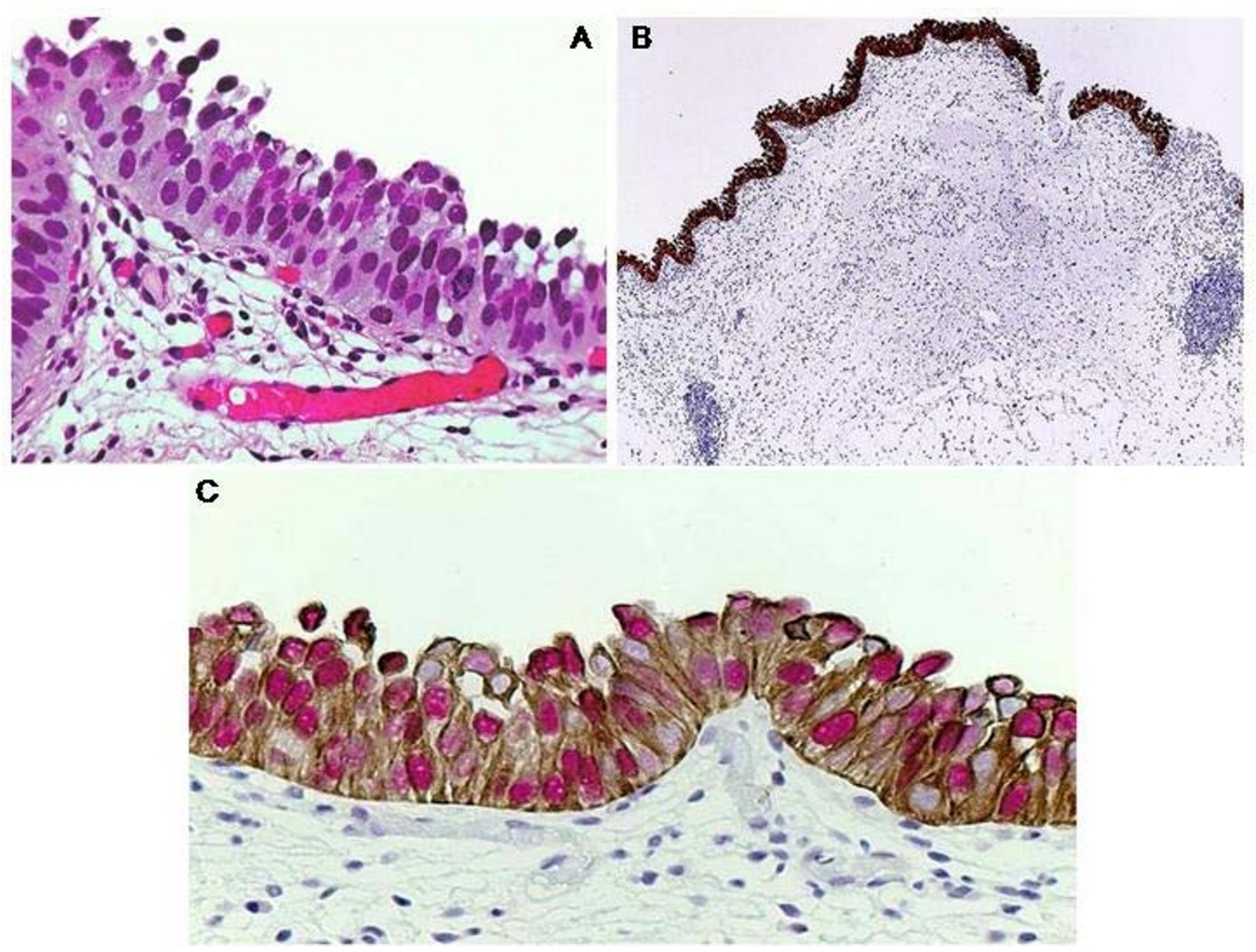

\section{Figure 3}

CIS (carcinoma in situ) in urothelium (A) (hematoxylin eosin, original magnification $\times 400)$. Cytoplasmic fullthickness immunoreactivity to CK20 and nuclear 3+ immunoreactivity to p53 (B and C) (original magnification $\times 40$ (B), $\times 400$ (C)).

ransky and Wright et al. $[21,28,30]$. In nonneoplastic and reactive urothelium, expression of p53 has been described as varying from negative to weak and patchy, predominantly in basal and parabasal intermediate cells $[9,11,31]$. In parallel to these results, $60 \%(21 / 35)$ of the benign/ reactive group cases of our study were found to be $\mathrm{p} 53(-)$. In contrast, p53 was considered positive by Mallofre in $80 \%$ of the CIS cases, with $70 \%$ of those cases showing positivity in $50 \%$ of the cells [11]. Similarly, McKenney found that p53 was positive in $57 \%$ of the CIS cases, with all of the cases exhibiting positivity in more than $50 \%$ of malignant cells [9]. In our study, $10 \%(1 / 10)$ of the dysplasia, 67\% (6/9) of CIS and 29\% (2/7) of invasive carcinoma cases showed strong diffuse p53 positivity whereas another 29\% (2/7) of invasive carcinoma cases exhibited moderate $\mathrm{p} 53$ positivity.
If found in the cytoplasm of cells different than superficial umbrella cells and occasional intermediate cells, CK20 is considered abnormally expressed as a marker of abnormal urothelial differentiation [31,32]. Urothelial de-differentiation, as with neoplastic change, is accompanied by expression of CK20 in all cell layers as shown by Harnden et al. [8,32]. This change in the extent of expression makes CK20 a useful and reliable marker of the neoplastic change of urothelial cells [8,32-36]. Immunostaining for CK20 is therefore an important addition to morphology in the diagnosis of neoplasia, especially, in the differentiation from reactive states where diagnostic difficulties are greatest $[8,37]$. Cases of atypia and dysplasia that display abnormal CK20 staining should raise the possibility of CIS and be followed up appropriately. In the studies of Mckenney, Mallofre and Kunju et al it has been reported that in nonneoplastic epithelium as well as the reactive 


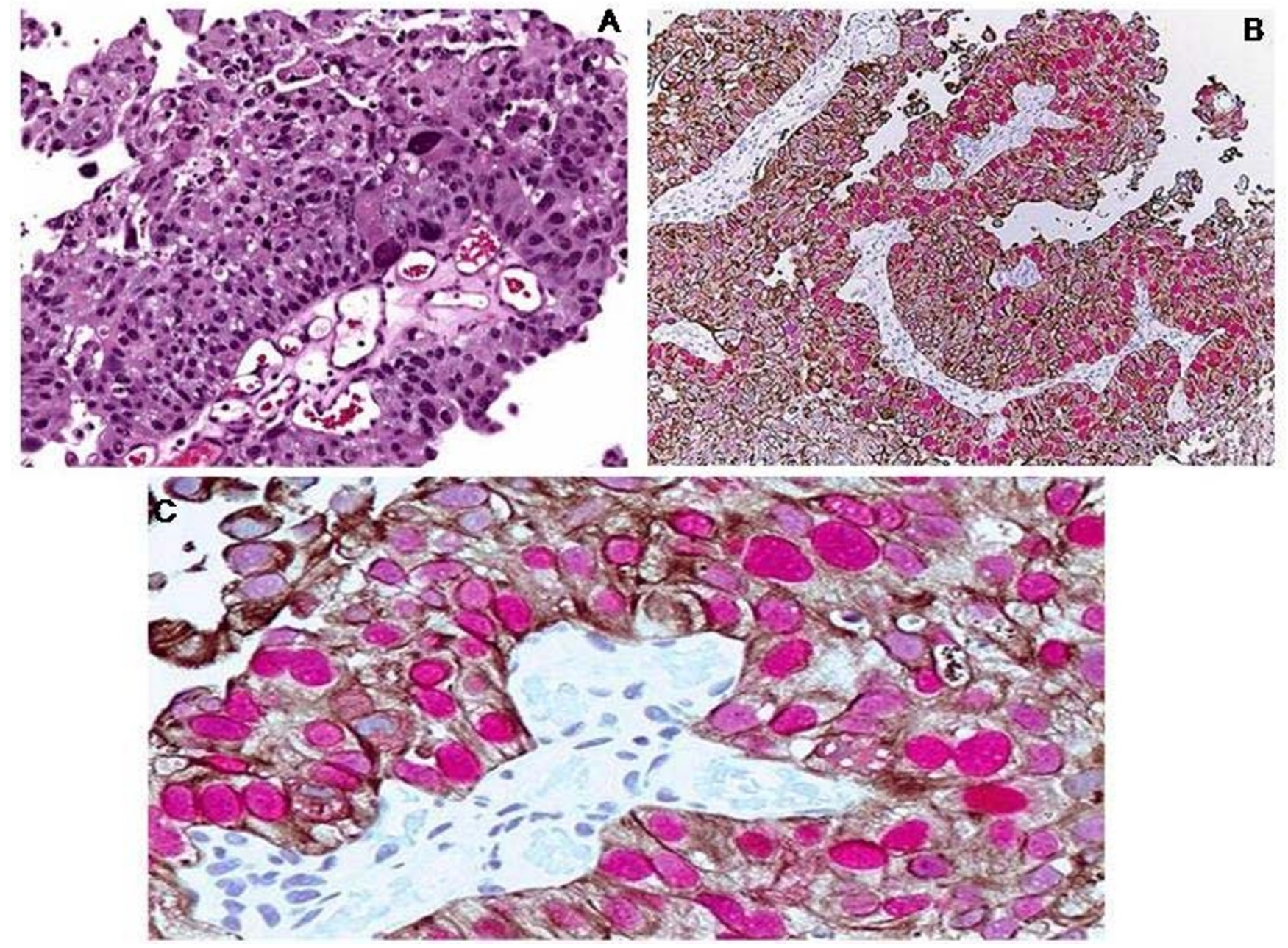

Figure 4

Invasive carcinoma (A) (hematoxylin eosin, original magnification $\times \mathbf{2 0 0}$ ). Cytoplasmic full-thickness immunoreactivity to CK20 and nuclear 3+ immunoreactivity to p53 (B and C) (original magnification $\times 100$ (B), $\times 400$ (C)).

urothelium CK20 showed patchy cytoplasmic immunoreactivity in only the superficial umbrella cell layer $[9,11,37]$. In favor of those studies, in our study, we found that $92 \%(35 / 38)$ of benign/reactive cases were either CK20(-) or showed CK20 positivity only in the upper 1/3 urothelium. While confined to superficial umbrella cells in normal urothelium, CK20 has been reported to show diffuse full thickness staining in $72-89 \%$ of cases of CIS and has also been reported to be expressed in $22-58 \%$ of invasive urothelial carcinomas [7,9,11,37-39]. However, CK20 immunoexpression was found to be nondiscriminatory in 11-28\% of CIS cases due to lack of CK20 expression $[7,9,11,37]$. In this study, abnormal expression of CK 20 was found in $90 \%(9 / 10)$ of dysplasia, $89 \%(8 / 9)$ of CIS and 71\% (5/7) of IC cases whereas the rest of the cases lacked abnormal CK20 expression.

\section{Conclusion}

According to our results, we can conclude that our proposed immunohistochemical panel composed of p53 and CK20 for studying dysplastic urothelial changes is adequate and useful for confirming the presence of dysplastic changes in the urothelium and can be of aid in better defining the histological criteria of urothelial dysplasia.

Furthermore, our studies have demonstrated that p53+CK20 cocktail (if commercially available) may be a useful diagnostic marker in the assessment of bladder biopsies. Two markers, in our opinion, could be used in routine practice, together with careful clinical and morphologic correlation. p53+CK20 DIHC can be considered as a useful innovation in differentiating non-neoplastic vs. neoplastic lesions in bladder biopsies enhancing the credibility of the diagnosis and reducing the number of 


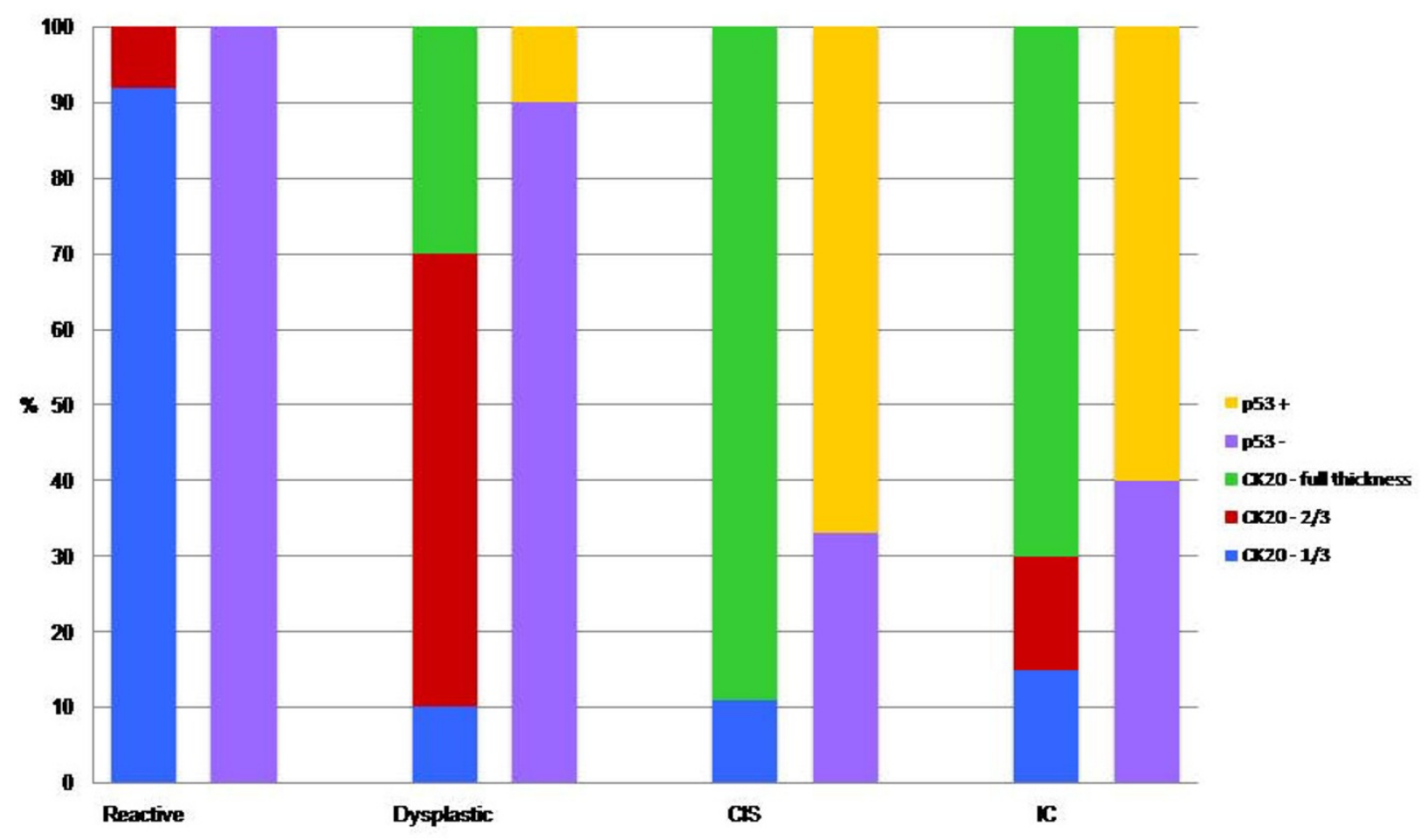

Figure 5

The distribution of location of CK20 staining in the urothelium and presence of p53 staining (0 and I+ staining = p53 -, 2+ and 3+ staining = p53 +) according to diagnosis (CIS: carcinoma in situ and IC:invasive carcinoma) groups.

inconclusive pathology reports of atypia of unknown significance consequently minimizing the need for rebiopsy as the dual staining not only allows for histologic correlation but also diminishes the risk of losing the area of interest in limited biopsy specimens in recut sections.

\section{Abbreviations}

DIHC: Double immunohistochemistry; CIS: Carcinoma in situ; IC: invasive carcinoma; WHO/ISUP: World health organization/international society of urological pathology; RUA: Reactive urothelial atypia; AUS: Atypia of unknown significance; UD: Urothelial dysplasia; IHC: Immunohistochemistry.

\section{Competing interests}

The authors declare that they have no competing interests.

\section{Authors' contributions}

IZY collected the background references, wrote the discussion of the results, created the sequence of alignment and drafted the manuscript. RR obtained the diagnostic material from the archive of the pathology department, carried out the immunohistochemical tests and pathological examination, took the photomicrographs and displayed the results of the study. HBA contributed to the prepara- tion of the manuscript. SB, RD and AVP participated in the design and coordination of the study and gave and reviewed the final histopathological diagnosis. AVP revised the manuscript. All authors read and approved the final manuscript.

\section{References}

I. Eble JN, Sauter G, Epstein JI, Sesterhenn IA: World Health Organization Classification of Tumours: Pathology and Genetics of Tumours of the Urinary System and Male Genital Organs Lyon: IARC Press; 2004.

2. American Cancer Society: Cancer Facts \& Figures 2008 Atlanta:American Cancer Society; 2008.

3. Epstein JI, Amin MB, Reuter VR, Mostofi FK: The World Health Organization/International Society of Urological Pathology consensus classification of urothelial (transitional cell) neoplasms of the urinary bladder. Bladder Consensus Conference Committee. Am J Surg Pathol I998, 22:1435-48.

4. Cheng L, Cheville JC, Neumann RM, Bostwick DG: Natural history of urothelial dysplasia of the bladder. Am J Surg Pathol 1999. 23:443-7.

5. Cheng L, Cheville JC, Neumann RM, Leibovich BC, Egan KS, Spotts $B E$, Bostwick DG: Survival of patients with carcinoma in situ of the urinary bladder. Cancer 1999, 85:2469-74.

6. McKenney JK, Gomez JA, Desai S, Lee MW, Amin MB: Morphologic expressions of urothelial carcinoma in situ: a detailed evaluation of its histologic patterns with emphasis on carcinoma in situ with microinvasion. Am J Surg Pathol 2001, 25:356-62.

7. Yin $\mathrm{H}, \mathrm{He} \mathrm{Q}, \mathrm{Li}$ T, Leong AS: Cytokeratin 20 and Ki-67 to distinguish carcinoma in situ from flat non-neoplastic urothelium. Appl Immunohistochem Mol Morphol 2006, I 4(3):260-5. 
8. Harnden P, Eardley I, Joyce AD, Southgate J: Cytokeratin 20 as an objective marker of urothelial dysplasia. $\mathrm{Br} J$ Urol 1996, 78:870-75.

9. McKenney JK, Desai S, Cohen C, Amin MB: Discriminatory immunohistochemical staining of urothelial carcinoma in situ and non-neoplastic urothelium: an analysis of cytokeratin 20, p53, and CD44 antigens. Am J Surg Pathol 200I, 25:1074-8.

10. Sun W, Zhang PL, Herrera GA: p53 protein and Ki-67 overexpression in urothelial dysplasia of bladder. Appl Immunohistochem Mol Morphol 2002, 10:327-31.

II. Mallofre C, Castillo M, Morente V, Sole M: Immunohistochemical expression of CK20, p53, and $\mathrm{Ki}-67$ as objective markers of urothelial dysplasia. Mod Pathol 2003, 16:187-9I.

12. Retz M, Lehmann J, Amann E, Wullich B, Roder C, Stockle M: Mucin $\mathbf{7}$ and cytokeratin $\mathbf{2 0}$ as new diagnostic urinary markers for bladder tumor. J Urol 2003, 169:86-9.

13. Bostwick DG: Natural history of early bladder cancer. J Cell Biochem I992, I 6 I (suppl):3 I-8.

14. Farrow GM, Utz DC, Rife CC, Greene LF: Clinical observations on sixty-nine cases of in situ carcinoma of the urinary bladder. Cancer Res 1977, 37:2794-8.

15. Troxel DB: Suits \& Briefs. CAP Today 2000, 14:88.

16. Jin B, Zaidi SY, Hollowell M, Hollowell C, Saleh $\mathrm{H}$ : A unique case of urinary bladder simple melanosis: a case report and review of the literature. Diagn Pathol 2009, 4:24.

17. Pradhan D, Kakkar N, Bal A, Singh SK, Joshi K: Sub-typing of renal cell tumours; contribution of ancillary techniques. Diagn Pathol 2009, 4:2।.

18. Nese N, Gupta R, Bui MH, Amin MB: Carcinoma in situ of the urinary bladder: review of clinicopathologic characteristics with an emphasis on aspects related to molecular diagnostic techniques and prognosis. J Natl Compr Canc Netw 2009, 7(I):48-57.

19. Iggo R, Gatter K, Bartek J, Lane D, Harris AL: Increased expression of mutant forms of p53 oncogene in primary lung cancer. Lancet 1990, 335:675.

20. Lohmann D, Ruhri C, Schmitt M, Graeff H, Höfler H: Accumulation of $\mathrm{p} 53$ protein as an indicator for $\mathrm{p} 53$ gene mutation in breast cancer: occurrence of false-positives and false negatives. Diagn Mol Pathol 1993, 2:36.

21. Sidransky D, von Eschenbach A, Tsai YC, Jones P, Summerhayes I, Marshall F, Paul M, Green P, Hamilton SR, Frost P, et al:: Identification of $\mathrm{p} 53$ gene mutations in bladder cancers and urine samples. Science |99|, 25:705-709.

22. Krause FS, Feil G, Bichler KH: Immunohistochemical examinations (Ki67, p53, nm23) and DNA cytophotometry in bladder cancer. Anticancer Res 2000, 20:5023-5028.

23. Tut VM, Braithwaite KL, Angus B, Neal DE, Lunec J, Mellon JK: Cyclin DI expression in transitional cell carcinoma of the bladder: correlation with p53, wafI, pRb and Ki67. Br J Cancer 200I, 84:270-275.

24. Cina SJ, Lancaster-Weiss KJ, Lecksell K, Epstein Jl: Correlation of Ki67 and p53 with the new World Health Organization/ International Society of Urological Pathology classification system for urothelial neoplasia. Arch Pathol Lab Med 200I, | 25:646-65|.

25. Fujimoto K, Yamada Y, Okajima E, Kakizoe T, Sasaki H, Sugimura T, Terada M: Frequent association of $p 53$ gene mutation in invasive bladder cancer. Cancer Res 1992, 52:1393-1398.

26. Pich A, Chiusa L, Formiconi A, Galliano D, Bortolin P, Navone R: Biological differences between noninvasive papillary urothelial neoplasms of low malignant potential and low-grade (grade I) papillary carcinomas of the bladder. Am J Surg Pathol 200I, 25:1528-1533.

27. Cordon-Cardo C, Reuter V: Alterations of tumor suppressor genes in bladder cancer. Semin Diagn Pathol 1997, 14:123-32.

28. Wright C, Mellon K, Johnston P: Expression of mutant p53, cerb-B2 and epidermal growth factor receptor in transitional cell carcinoma of the human urinary bladder. Br J Cancer I991, 63:967-70

29. Sarkis AS, Dalbagni G, Cordon-Cardo C, Melamed J, Zhang ZF, Sheinfeld J, Fair WR, Herr HW, Reuter VE: Association of p53 nuclear overexpression and tumor progression in carcinoma in situ of the bladder. J Urol 1994, I 52:388-92.

30. Olumi AF, Tsai YC, Nichols PW, Skinner DG, Cain DR, Bender LI, Jones PA: Allelic loss of chromosome 17p distinguishes high grade from low grade transitional cell carcinomas of the bladder. Cancer Res 1990, 50:708I-7083.

3I. Yin $H$, Leong AS: Histologic grading of noninvasive papillary urothelial tumors: validation of the 1998 WHO/ISUP system by immunophenotyping and follow-up. Am J Clin Pathol 2004, | 2 | (5):679-87.

32. Harnden P, Mahmood N, Southgate J: Expression of cytokeratin 20 redefines urothelial papillomas of the bladder. Lancet 1999, 353:974-977.

33. Chu P, Wu E, Weiss LM: Cytokeratin $\mathbf{7}$ and cytokeratin 20 expression in epithelial neoplasms: a survey of 435 cases. Mod Pathol 2000, 13(9):962-72.

34. Desai S, Lim SD, Jimenez RE, Chun T, Keane TE, McKenney JK, Zavala-Pompa A, Cohen C, Young RH, Amin MB: Relation of cytokeratin 20 and CD44 protein expression with WHO/ISUP grade PTa and pTI papillary urothelial neoplasia. Mod Pathol 2000, 13(I 2): I3|5-23.

35. Klein A, Zemer R, Buchumensky V, Klaper R, Nisserkon I: Expression of cytokeratin 20 in urinary cytology of patients with bladder carcinoma. Cancer 1998, 82:349-54.

36. Alsheik A, Mohamedali Z, Jones E, Masterson J, Gilks CB: Comparison of the WHO/ISUP classification and cytokeratin expression in predicting the behaviour of low-grade papillary urothelial tumors. Mod Pathol 200I, I4(4):267-72.

37. Kunju LP, Lee CT, Montie J, Shah RB: Utility of cytokeratin 20 and Ki-67 as markers of urothelial dysplasia. Pathol Int 2005, 55(5):248-54

38. Genega EM, Hutchinson B, Reuter VE, Gaudin PB: Immunophenotype of high-grade prostatic adenocarcinoma and urothelial carcinoma. Mod Pathol 2000, I 3:1 I86-91.

39. Parker DC, Folpe AL, Bell J, Oliva E, Young RH, Cohen C, Amin MB Potential utility of uroplakin III, thrombomodulin, high molecular weight cytokeratin, and cytokeratin 20 in noninvasive, invasive, and metastatic urothelial (transitional cell) carcinomas. Am J Surg Pathol 2003, 27:1-10.
Publish with Bio Med Central and every scientist can read your work free of charge

"BioMed Central will be the most significant development for disseminating the results of biomedical research in our lifetime."

Sir Paul Nurse, Cancer Research UK

Your research papers will be:

- available free of charge to the entire biomedical community

- peer reviewed and published immediately upon acceptance

- cited in PubMed and archived on PubMed Central

- yours - you keep the copyright 